\title{
News from China
}

\section{China received over 928,000 invention patent applications in 2014}

According to the data from SIPO, in 2014 China received 928,000 invention patent applications, showing an annual growth of $12.5 \%$. In these applications, 801,000 were domestic, accounting for $86.3 \%$ and 127,000 were foreign, accounting for $13.7 \%$. There were 233,000 invention patents granted, displaying a growth of $12.3 \%$. In the granted patents, 163,000 were domestic, accounting for $70 \%$, and 70,000 were international, accounting for $30 \%$.

China's invention patent applications were increasing stably in the past year. In 2014, the growth rate of patent applications was $12.5 \%$, lower than the average rate of over $20 \%$.

In 2014, the growth rate of Chinese invention patent granted was $12.3 \%$, higher than the average. It showed that China improved more and more in its patent examination capacity.

In 2014, invention patents accounted for $39.3 \%$ of all patent applications, surpassing that of utility model applications, which accounted for $36.8 \%$. These figures display an improvement in field of Chinese innovation, with inventions playing a more central role.

In 2014, the percentages of domestic applications and granted patents were both increasing, respectively $86.3 \%$ and $70 \%$.

In addition, enterprises filed the most invention patent applications. Chinese enterprises filed 485,000 applications, accounting for $60.5 \%$ of the total. 92,000 patents were granted, accounting for $56.4 \%$ of the total granted patents, with an increase of $1.5 \%$ from the previous year.

http://english.sipo.gov.cn/news/official/201502/t20150204_ 1071502.html

\section{China granted 233,000 invention patents in 2014}

State Intellectual Property Office (SIPO) in Beijing released the 2014 statistics of granted invention patents on February 11, 2015. In 2014, SIPO received 928,000 invention patent applications, up 12.5 percent from the previous year. China has been the world leader in patent applications for four years in a row. In total, China granted 233,000 invention patents in 2014. In these patents, 163,000 patents were domestic, increasing nearly 20,000 compared with those of last year. The valid domestic (excluding Hong Kong, Macao and Taiwan) invention patents totaled 663,000 by the end of 2014 . An amount equaled to 4.9 patents per 10,000 people.

The granted patent numbers of provinces/municipalities (excluding Hong Kong, Macao and Taiwan) and enterprises are of great interest to the public. Among the top ten provinces which were granted the most invention patents in 2014, Beijing ranks number one with 23,237 patents, and for the second time surpassing Guangdong. Guangdong and Jiangsu occupy second and third place respectively. Zhejiang, Shanghai, Shandong and Sichuan stands the forth to the seventh, with Anhui ranking eighth for the second time. Shaanxi and Hubei are ninth and tenth on the list. In the top ten enterprise ranking, Huawei remains the dominant leader followed by ZTE, Sinopec, Hongfujin, Oceans King Lighting, BOE, CNPC (China National Petroleum Corporation), SGCC (State Grid Corporation of China), CSOT, China Star Optoelectronics Technology, and $\mathrm{H} 3 \mathrm{C}$.

SIPO has also released statistics on the top ten provinces/municipalities with the most invention patents by the end of 2014. The ranking is as follows: Guangdong (111,878), Beijing (103,638), Jiangsu (81,114), Shanghai $(56,515)$, Zhejiang $(52,418)$, Shandong $(34,775)$, Sichuan $(21,209)$, Hubei $(18,825)$, Liaoning $(18,417)$ and Shaanxi (17,575).

SIPO accepted 26,169 PCT applications in 2014, an increase of $14.2 \%$ from the previous year. There were 18 provinces/municipalities that had more than 100 PCT applications. Guangdong was the leader with 13,332 PCT applications. Beijing, Jiangsu, Shanghai and Zhejiang ranked second to fifth, with PCT application numbers of above five provinces/municipalities accounting for $85 \%$ of the total.

http://www.sipo.gov.cn/zscqgz/2015/201502/t20150212_ 1075284.html

Zhou Tao

Chengdu Documentation and Information Center, Chinese Academy of Sciences

\section{China made remarkable progress in $\mathbf{2 0 1 4}$ with intellectual property financial services}

2014 was a productive year for IPR financial services. Statistics from SIPO show that Chinese companies have secured a 48.9 billion RMB patent credit line, up 92.5\%. An increase of 31.3\% was shown with 1850 Micro, Small and Medium-Sized Enterprises (MSMEs). Patent insurance services also made breakthroughs last year in the areas including patent enforcement insurance, patent infringement liability insurance, intellectual property general liability insurance, and IP pledge financing insurance services. There have been currently 798 MSMEs investing 134 million RMB for patent insurance. The number of patent enforcement insurance companies has increased $45.7 \%$ from last year.

In 2014, SIPO instituted policies to promote the innovation development of MSMEs and to improve the IPR financial service system.

SIPO enhanced the IP mortgage financing system and organized agencies to provide legal advice and assessment analysis. In the same time, by accelerating patent insurance market cultivation, deepening cooperation with insurance agencies, promoting 
innovation through patents insurance coverage, optimizing operational mode, and simplifying claims procedures, the intellectual property legal risk awareness of enterprises has been strengthened.

http://www.sipo.gov.cn/zscqgz/2015/201501/t20150129_ 1069140.html

Zhou Tao

Chengdu Documentation and Information Center, Chinese Academy of Sciences

\section{New provisions for the deposit of biological materials for patent procedures implemented}

On January 16, 2015, according to the Sixty-Ninth Order of State Intellectual Property Office (SIPO), the new Provisions for Deposit of Biological Materials for the Purposes of Patent Procedure ("Provisions") were passed. The new provisions took effect on March 1, 2015. It was the first time that provisions for biological materials preservation in patent process were revised in the past 30 years.

In 1985, the Patent Office of People's Republic of China created the Eighth Notice, known as the Provisions for Deposit of Biological Microorganisms for the Purpose of Patent Procedures. With China being a member of Budapest Treaty on the International Recognition of the Deposit of Microorganisms for the Purposes of Patent Procedure in 1995 and changes of patent applicants' and patent assignees' demands, China's Eight Notice was insufficient. To remedy this problem, SIPO launched a program to revise the biological materials preservation provisions in early 2014.

The revision is established on the basis of current patent law and its implementation rules with the full consideration of the Budapest Treaty on the International Recognition of the Deposit of Microorganisms for the Purposes of Patent Procedure. Compared with the Eighth Notice, the major changes are as follows:

(1) The stylistic rules and layout of the "Provisions" are modified;

(2) The duties of preservation units are specified;

(3) Appellations are standardized;

(4) Situations in which samples cannot be withdrawn during the preservation period are pinpointed;

(5) Circumstances in which samples cannot be preserved are specified.

(6) The time limit of preservation units' confidentiality duties is modified.

(7) The provisions on providing samples of the biological material are improved.

(8) The disposal methods for biological materials after the preservation period are specified.

http://www.sipo.gov.cn/zscqgz/2015/201502/t20150204_ 1071415.html

http://www.sipo.gov.cn/zwgg/jl/201501/t20150123_1065907. html html

http://www.sipo.gov.cn/mtjj/2014/201411/t20141105_1027467.

Ying-Qi Xu

Chengdu Documentation and Information Center, Chinese Academy of Sciences

\section{A brief introduction to guideline on promoting the establishment of standardized intellectual property right service system}

On December 31, 2014, according to a series of requirements to strengthen standardization work proposed by the State Council and relevant ministries, State Intellectual Property Office (SIPO), Standardization Administration of China, State Administration for Industry and Commerce of China and National Copyright Administration of China jointly released Guideline on Promoting the Establishment of Standardized Intellectual Property Right Service System ("Guideline”), to establish standardized intellectual property right (IPR) service system of China. The two-stage construction goals are put forward in "Guideline". The first stage involves the initial establishment of a standardized IPR service system by 2017. In the second stage, the established system is modified, perfected, and fully implemented before 2020.

In "Guideline", it is pointed out that the establishment of standardized IPR service system plays important roles in promoting the healthy development of IPR services, regulating behavior of intellectual property service, improving the quality and efficiency of services, raising ability and level of services, perfecting the market environment and strengthening self-discipline.

Five key tasks of IPR service standardization are specified in the "Guideline", including building technology organization, enhancing $\mathrm{R} \& \mathrm{D}$, fostering pilot programs, strengthening cultivation of talents, and improving propaganda and implementation. The IPR service standard system framework is constructed from three main parts, that is, general standards, business supporting standards, and service providing standards. These standards are put forward with nine revision tasks of IPR service standards containing general standards, business supporting standards, intellectual property agency services, intellectual property legal services, intellectual property information services, intellectual property commercialization services, intellectual property consulting services, intellectual property training services, and intellectual property public services. By strengthening policy support, improving the operational mechanism, strengthening financial security, promoting international exchange and other security measures, the construction of IPR service system is on the road to success.

According to the degree of market demand for IPR service standards, the SIPO, Standardization Administration of China and other relevant ministries will accelerate a number of IPR service standards to be issued. For unifying general terms and abbreviations standards for IPR services, the common terminology criteria for IPR services will be formulated. In order to improve the quality of patent application agency service and to standardize the agency service market, the quality criteria for patent agency service will be promulgated. The criteria for patent information retrieval and analysis services will be issued, in order to regulate the service level, process, quality, operation management, service evaluation and improvement of patent information retrieval and analysis in the process of patent information service. html

http://www.sipo.gov.cn/zcfg/zcjd/201501/t20150122_1065553.

http://english.sipo.gov.cn/news/official/201501/t20150130_ 1069435.html

Ying-Qi Xu

Chengdu Documentation and Information Center, Chinese Academy of Sciences

Zhi-Ping Yang*, Tao Zhou, Ying-Qi Xu Chengdu Documentation and Information Center, Chinese Academy of Sciences, China

\author{
* Corresponding author. \\ E-mail address: yangzp@yahoo.com (Z.-P. Yang).
}

